\title{
Numerical simulation of formation damage by drilling fluid in low permeability sandstone reservoirs
}

\author{
Weiwei He ${ }^{1}$ Zhiqiang Liu $^{2}$
}

Received: 19 January 2021 / Accepted: 7 March 2021 / Published online: 24 March 2021

(c) The Author(s) 2021

\begin{abstract}
Understanding the formation damage surrounding the well during the drilling operation is the key to predict damage degree and protect the formation in oil/gas reserviors. Based on the core drainage results, we obtained an empirical relationship between the invasion volume of drilling fluid and permeability reduction of formation. Furthermore, the equation is incorporated into a commercial reservior numerical simulation simulator to characterize the behaviors of drilling fluid invasion process. The results show that, although the invasion depth in low permeability reservoirs is short with the range of 1.7-2.5 m, the effect on recovery factor is significant due to the narrow seepage area in the near fracture region. When considering the formation damage, the pressure in the near-fracture damage region drops sharply, leading to a three-stage shape in pressure distribution curve. In addition, we found that high viscosity and low density oil-based slurry and shorter soaking period are conducive to decrease the formation damage during drilling operation. This work reveals the fundamental mechanisms of formation damage in low permeability reservoirs, which is a theoretical basis in formulation drilling fluids and optimization operation parameters.
\end{abstract}

Keywords Low permeability reservoirs $\cdot$ Formation damage $\cdot$ Numerical simulation $\cdot$ Drilling fluid

\section{Introduction}

The oil/gas in low permeability reservoir, as one of the important fossil fuels, has a great deal of resources in worldwide (Xu et al. 2016). Compared with conventional oil/gas reservior, the low permeability reservior has stronger formation heterogeneity with complex pore-throat structure (AlYaseri et al. 2015; Kamal et al. 2019; Zhao et al. 2019). As a result, the property of the low permeability reservoir is very sensitive to the external fluid (Bazin et al. 2010; Mahmoud et al. 2016; Liang et al. 2017; Zhang et al. 2020a). For example, the reservoir formation can be severely damaged due to the invasion of drilling fluid during the drilling operation (Coskuner 2004).

Generally, the formation damage by drilling fluid in low permeability reservoirs can be classified into three types:

Weiwei He

vivian820626@163.com

1 School of Mechatronic Engineering, Daqing Normal University, Daqing 163453, China

2 Logging and Testing Services Company, Daqing Oilfield Company Ltd, Daqing 163000, China
(1) Formation damage by water blockage (Waldmann et al. 2005; Amani et al. 2012; Dias et al. 2015; Ahmad et al. 2017; Lu et al. 2021). The pore size distribution in low permeability reservoirs is very small with the range of microto nanometer (Su et al. 2018; Lyu et al. 2018; Zhang et al. 2020b). In addition, the minerals of the low permeability sandstone reservoirs tend to be strongly water-wet (Ballard and Dawe 1988; Yan et al. 1993). That is, the drilling fluid is easily to be imbibed into the formation triggered by the strong capillary pressure, blocking the effective flow pathways of the oil/gas from the deep reservoir into the wellbore. (2) Formation damage due to the swelling or migration of clay minerals (Clark 1995; Caenn and Chillingar 1996; Frequin et al. 2013; Ramézani et al. 2015). The clay minerals in low permeability reservoirs are usually rich, especially the sensitive clay minerals such as montmorillonite and kaolinite (Windarto et al. 2011; Windarto et al. 2012). After the introduction of drilling fluid, the balance between fluid and clay is broken (Doty 1986; Jiao and Sharma 1994; Iscan et al. 2007). The clay swelling (montmorillonite) can reduce the effective pore size and the particle migration (kaolinite) can block the pore throat completely, resulting in permanent reduction of formation permeability. (3) Formation damage

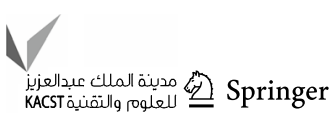


by the particle blockage from the drilling fluid (Growcock et al. 1994; Arhuoma et al. 2009; Van et al. 2012; Li et al. 2018). During the drilling, the introduction of rock debris into the drilling fluid is inevitable. Under the pressure difference between the drilling fluid and the formation, the rock debris and other solid particles can invade into the near-well formation, which affects the performance of the subsequent hydraulic fracturing (Whitaker 1996; Civan 1998; Jilani et al. 2002; Ding et al. 2004; Cai et al. 2010). Currently, the investigations for the formation damage induced by the drilling fluid are mostly from the perspective of laboratory experiments (Parn-Anurak and Engler 2005; Suryanarayana et al. 2007; Jin 2009; Shabani et al. 2019), and the numerical simulation study related to this topic is limited.

In this work, based on the results of core drainage experiments, an empirical equation between the permeability reduction and the invasion volume of drilling fluid is obtained. Then, the equation is incorporated into a commercial simulator to numerically characterize the invasion behaviors of drilling fluid in low permeability reservoirs. We quantified the effects of formation permeability, properties of drilling fluid (viscosity, density, etc.), and the soaking period on the damage radius, invasion volume, skin factor, and reduction degrees of recovery factor. Our investigation is conducive to predict the formation damage degrees and propose the corresponding strategies to mitigate the formation damage during drilling operation.

\section{Simulation methodology}

\section{Gridding and model set up}

We built a single porosity single permeability one-dimensional numerical model based on a commercial simulator IMEX ${ }^{\mathrm{TM}}$ from CMG. The model includes matrix and fracture where the fracture is located at the first grid near the well, as shown in Fig. 1. Considering the good symmetry of the reservoir after hydraulic fracturing and the available computation resources, we only model the invasion phenomenon for the near-well region by using one-dimensional model. In order to accurately capture the sudden variation of pressure and saturation in the near-well region, local grid refinement in a logarithmic form is applied to discretize the simulation domain to enhance the consistency and stability as well as to capture the transient flow. The grid size for the far end is $50 \mathrm{~m}$, while the grid size near the well is $0.008 \mathrm{~m}$, consistent with the real fracture width in the subsurface. The input data for the numerical model are the typical data for low permeability reservoir. There are two production layers with one having high permeability $(50 \mathrm{mD})$ and another one having low permeability $(30 \mathrm{mD})$. The thickness, porosity, fracture permeability of the both two layers are $13 \mathrm{~m}, 10 \%$ and $20 \mathrm{D}$, respectively. The formation depth is $4000 \mathrm{~m}$; reservoir pressure is $36.7 \mathrm{MPa}$; original water saturation is 0.25 ; rock compressibility coefficient is $4 \times 10^{-9} \mathrm{~Pa}^{-1}$. The pressure of drilling fluid in the simulation is $45 \mathrm{MPa}$ with soaking period of 1 week in the base case. The relative permeability and capillary pressure for the matrix are obtained by analytical equations. The capillary pressure curves considered the difference of imbibition (wetting phase as drainage fluid) and drainage (nonwetting phase as drainage fluid). In addition, exponential empirical formula is used to characterize the stress-dependent permeability of low permeability reservoir, and the detail parameters can be found in Zhang et al. 2017.

\section{Invasion equation from laboratory experiments}

Formation damage by drilling fluid is ascribed to the interaction between drilling fluid and clay minerals which causes clay swelling and clay migration to decrease permeability. In order to quantify the relationship between permeability reduction and invasion volume of drilling fluid, we conducted core invasion laboratory experiments. The core of the experiment is collected from the target reservoir as shown in Fig. 2. We inject polymer-based drilling fluid and measure the permeability of the core sample simultaneously, and the detail experimental apparatus, procedures, and cautions can be found in $\mathrm{Li}$ et al. (2017). After the fluid injection, the absolute permeability of the sample changed from 13 to $5.4 \mathrm{mD}$ with a permeability reduction of $58.3 \%$. The fitting empirical equation between the invasion volume and permeability can be shown as:

$$
\frac{K}{K_{0}}=\left\{\begin{array}{l}
1-\alpha \Omega\left(\Omega \leq \Omega_{0}\right) \\
1-\alpha \Omega_{0}\left(\Omega>\Omega_{0}\right)
\end{array}\right.
$$

Fig. 1 Numerical simulation model for low permeability reservoir with nonuniform grids

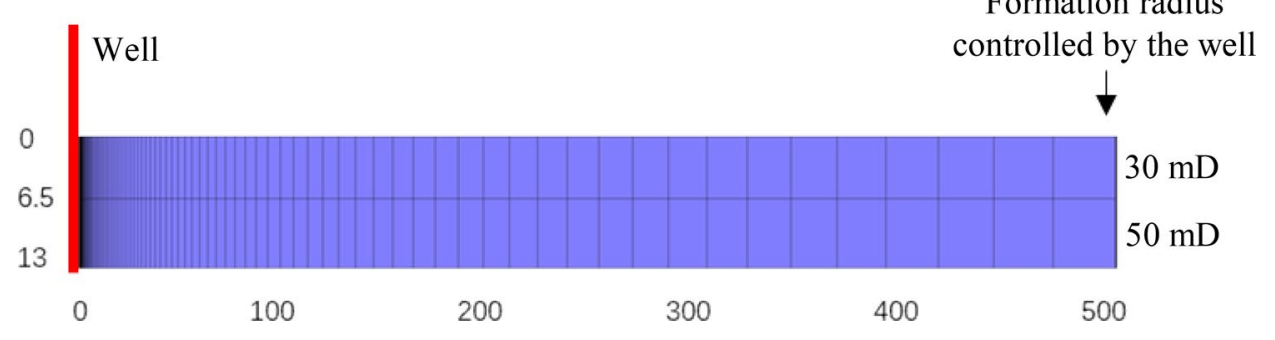




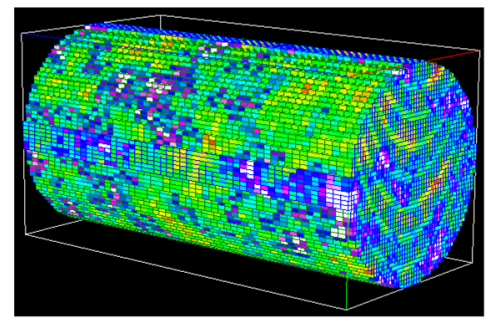

(a)

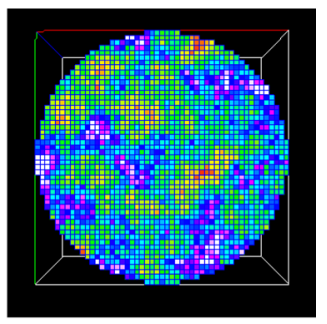

(b)
Fig. 2 Front $\mathbf{a}$ and side $\mathbf{b}$ view of the low permeability core used in the experiments

where $K_{0}$ is the original permeability; $K$ is the current permeability; $\Omega$ is the invasion volume; $\Omega_{0}$ is the saturated volume; the coefficient $\alpha$ is 0.15 . Therefore, by using the equation, the matrix permeability of the invaded region can be adjusted in real-time according to the invasion volume of drilling fluid, achieving the numerical simulation of formation damage caused by the drilling fluid.

\section{Results and discussion}

In this section, firstly, we characterized the invasion behaviors of drilling fluid by using the reservoir-scale numerical simulation; we quantified the invasion depth of the drilling fluid and its effects on the pressure distribution and the recovery factor. Furthermore, the effects of reservoir permeability, fluid properties (viscosity and density), and soaking period on the invasion characteristics were analyzed in detail.

\section{Invasion behaviors of drilling fluid}

Figure 3 presents the permeability and water saturation distribution in the near-well region after the invasion of drilling fluid. As we can see, due to the low permeability of the formation and imbibition hysteresis, the invasion depth is not very far which is mostly located at the near-well region. In the base case, the invasion depth of the drilling fluid is only in the range of 1.7-2.5 m after 7 days of soaking period. In addition, the total fluid invasion volume is $18.7 \mathrm{~m}^{3}$ including $11.9 \mathrm{~m}^{3}$ in high permeable layer and $6.8 \mathrm{~m}^{3}$ in low permeable layer. Because the matrix in the near-well region (within $1.5 \mathrm{~m}$ ) is fully saturated with drilling fluid, the formation damage is severe and the permeability reduces to the lowest limit, in which the permeability of high permeable layer reduced to $14.6 \mathrm{mD}$ and the permeability of low permeable layer reduced to $5.2 \mathrm{mD}$.

Figure 4 presents the pressure distribution in the nearwell region after the invasion of drilling fluid. If we ignore the formation damage in the simulation, the pressure curve exhibits two stages characteristics: a pressure-drop cone within the pressure interference region and a constant pressure in the far end of the reservoir. However, if we consider
Fig. 3 a Permeability and b water saturation distribution after the invasion of drilling fluid

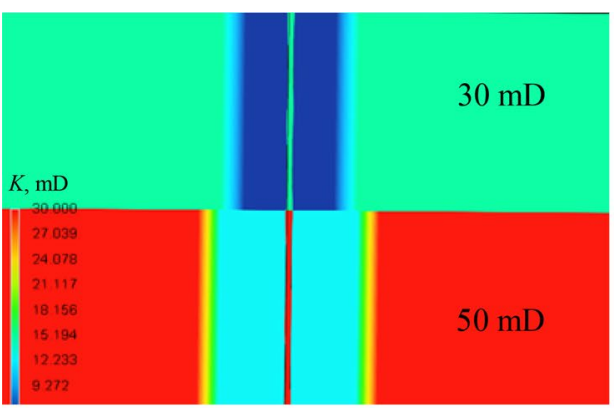

(a)

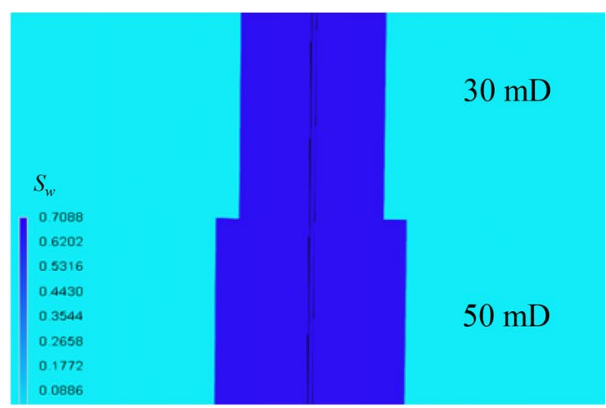

(b)
Fig. 4 Pressure distribution after the invasion of drilling fluid

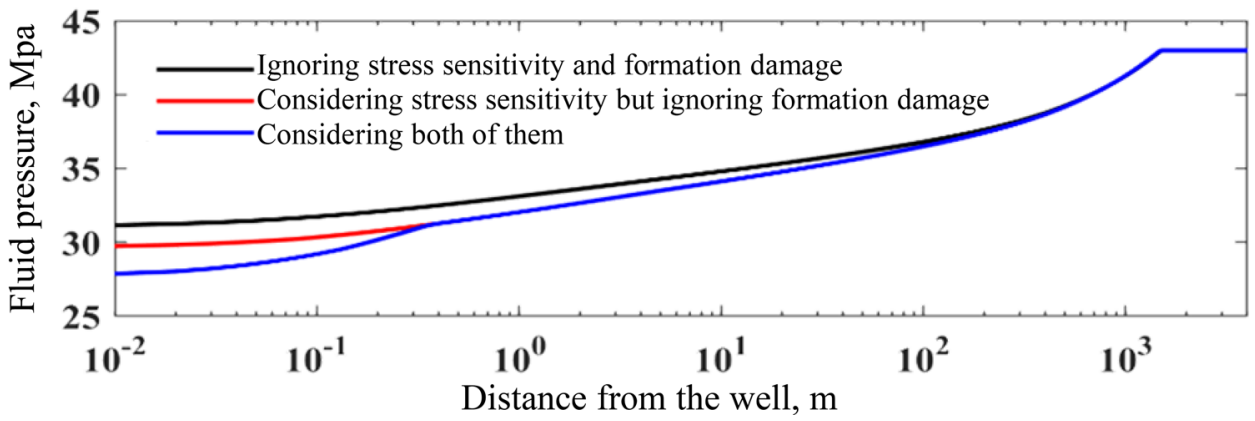


the formation damage in the simulation, the pressure curve exhibits three-stage characteristics. Besides the two stages mentioned above, a sharper reduction of pressure in the nearwell region can be observed where the flowing resistance of hydrocarbon is increased by the invasion of drilling fluid. Therefore, the invasion of drilling fluid increased the pressure consumption in the reservoir and decreased the effective drainage pressure during the production.

We also evaluated the effect of formation damage on the recovery factor of each layer, as shown in Fig. 5. The recovery factors for the simulated cases are smaller than $25 \%$, showing low recovery factor for the typical low permeability reservoir. The layer with high permeability produces hydrocarbon fasters at the early production stage, while the layer with low permeability produces most of the reserves at the late production stage. Finally, the recovery factor of the two layers is nearly same after 3500 days of continuous production. After considering the formation damage, the recovery factor would reduce at some extent, regardless of the original permeability of the formation. Especially, the reduction in the recovery factor of each layer at the early production stage can reach up to $3 \%$.

\section{Effects of permeability on fluid invasion}

To understand the effect of reservoir permeability on the drilling fluid invasion characteristics, we simulated a total number of 11 cases with permeability ranging from 1 to $40 \mathrm{mD}$ at same porosity of $10 \%$. The specific weight and viscosity of the cases are maintained as 1.01 and $50 \mathrm{cP}$, respectively. The reservoir matrix is exposed to the drilling fluid with 10 days, and the simulation has 10 years production. As shown in Fig. 6, the skin factor contributed by the stress-dependent permeability is stronger at a lower permeability, which is ascribed to the exponential form of stress-dependent equation. However, according to Eq. (1), the skin factor contributed by formation damage of drilling

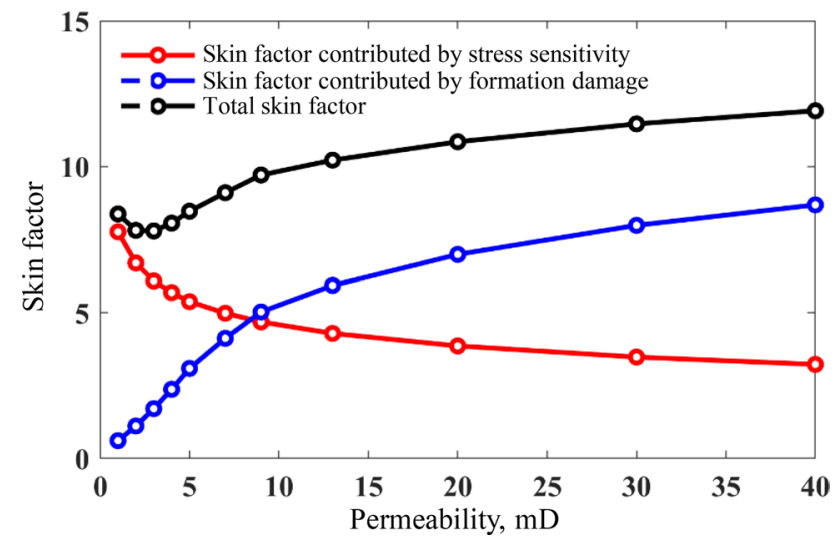

Fig. 6 Skin factor for different reservoir permeability

fluid decreases with the decrease in reservoir permeability. Therefore, the total skin factor decreases first then increases with the decrease of reservoir permeability. The effects of permeability on damage radius and reduction in recovery factor are shown in Fig. 7. With the increase in permeability, higher invasion volume of drilling fluid results in larger damage radius and subsequently higher reduction of recovery factor. For example, when the permeability is $40 \mathrm{mD}$, the damage radius can reach up to $400 \mathrm{~m}$, and the reduction of recovery factor is larger than $45 \%$.

\section{Effects of fluid properties on fluid invasion}

We evaluated the effects of drilling fluid properties (viscosity, specific weight) on the damage radius, invasion volume, skin factor, and reduction of recovery factor, as shown in Figs. 8 and 9. Higher viscosity of the drilling fluid indicates a larger flow resistance during invasion, which leads to a smaller invasion volume, damage radius, and reduction of recovery factor. Heavier specific weight of the drilling fluid results in a larger bottom-hole pressure, and the
Fig. 5 Effect of formation damage on the recovery factor of each producing layer. $N$ denotes ignoring formation damage, $D$ denotes considering formation damage

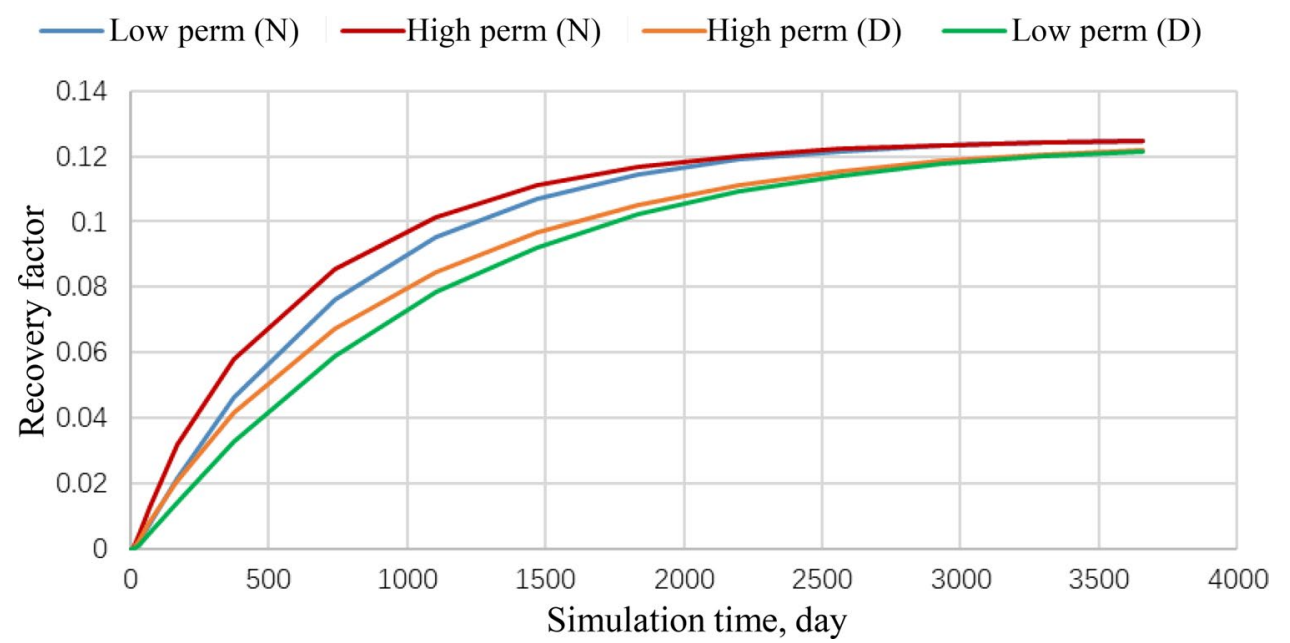




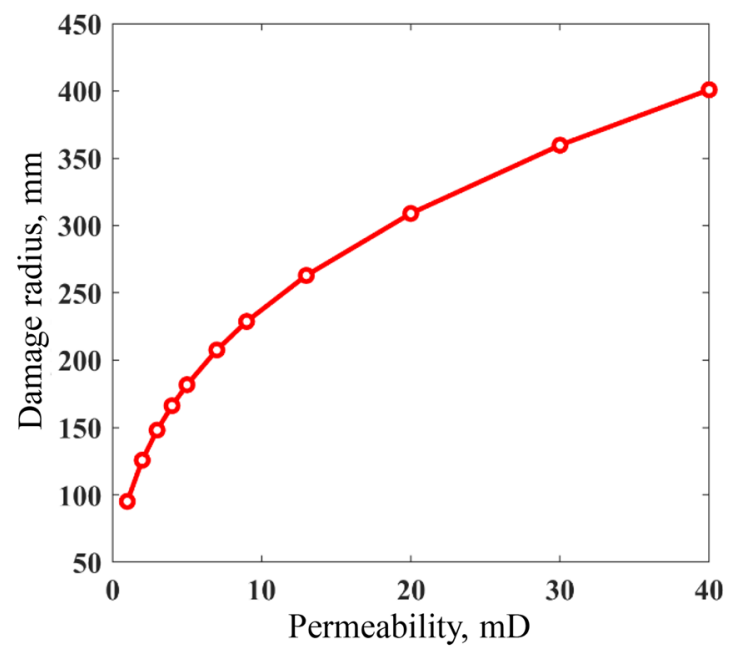

(a)

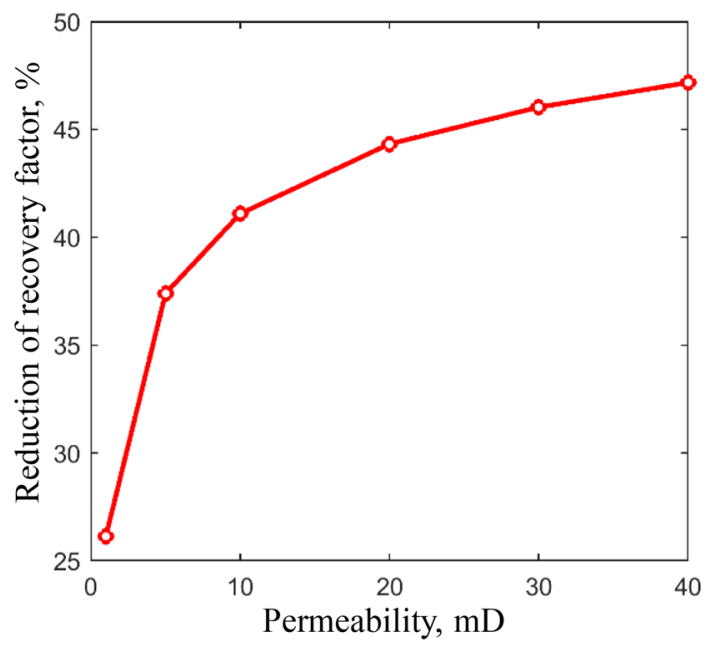

(b)

Fig. 7 a Damage radius and $\mathbf{b}$ reduction of recovery factor for different reservoir permeability

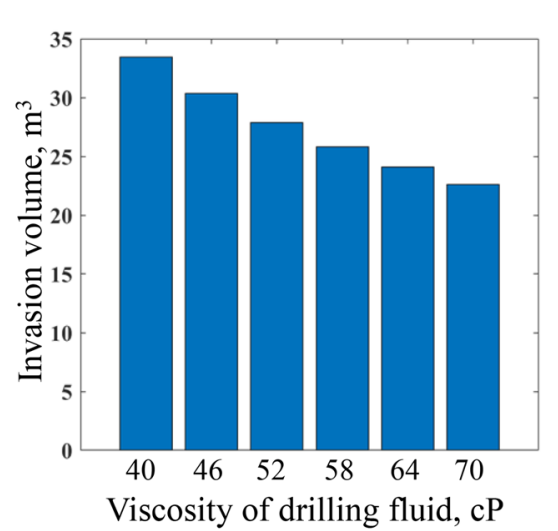

(a)

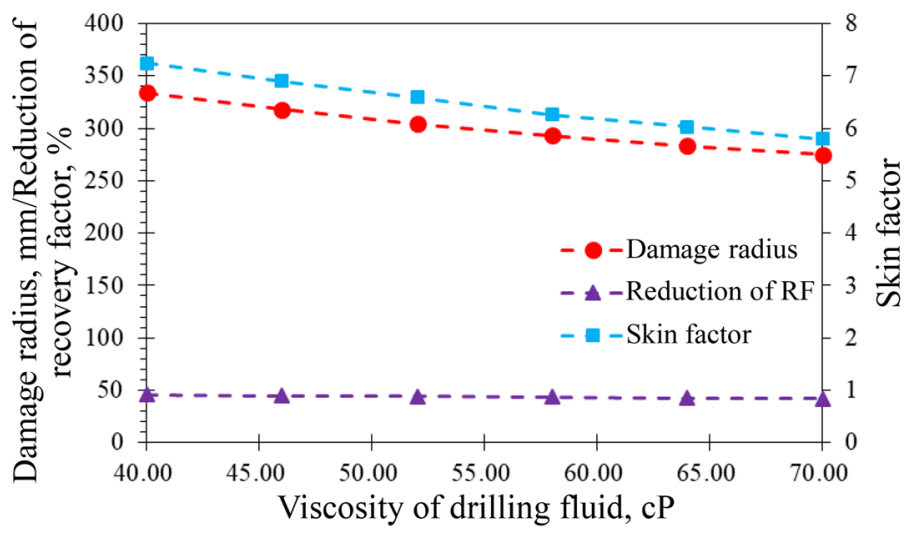

(b)

Fig. 8 Effects of drilling fluid viscosity on the formation damage

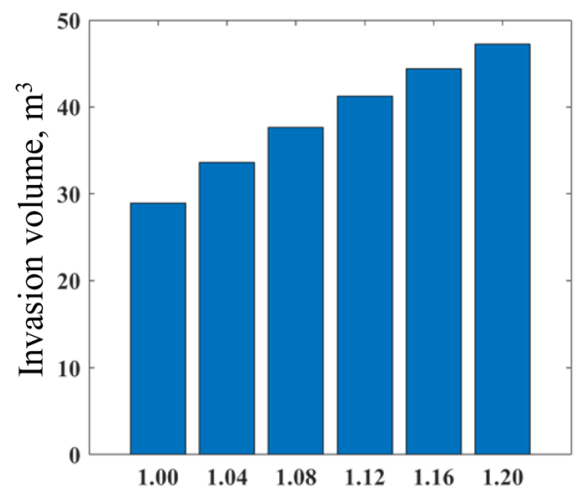

Specific gravity of drilling fluid, $\mathrm{cP}$

(a)

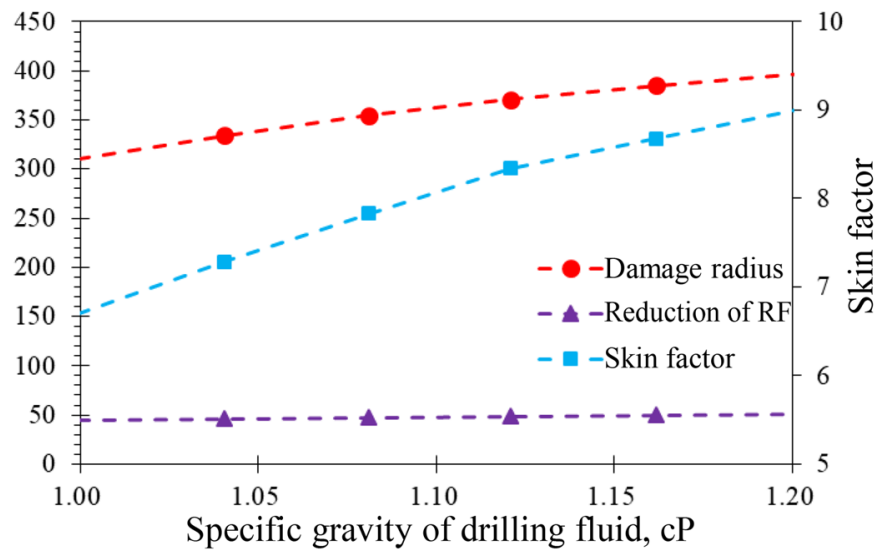

(b)

Fig. 9 Effects of drilling fluid density on the formation damage 


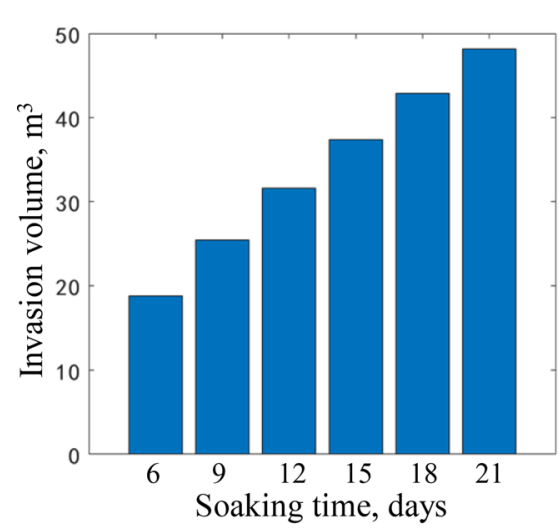

(a)

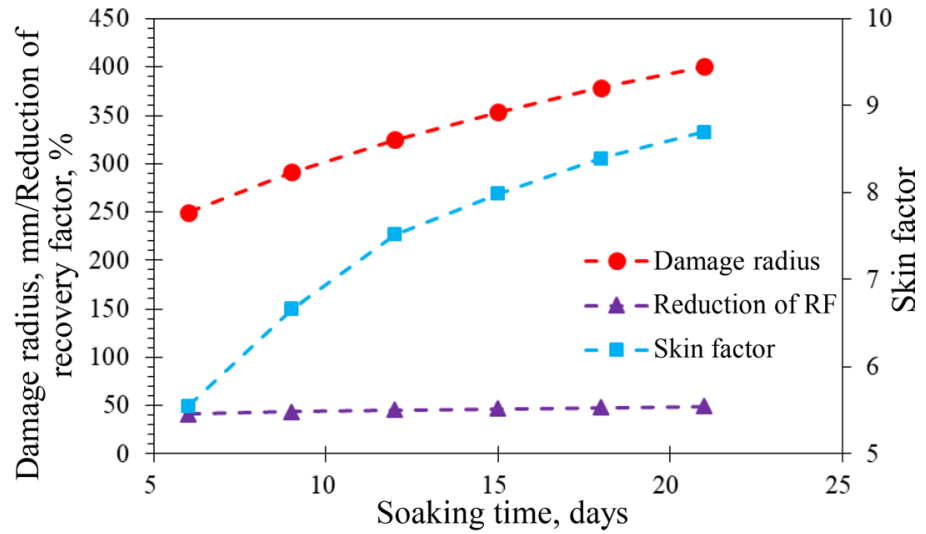

(b)

Fig. 10 Effects of soaking time on the formation damage

drainage pressure between the drilling fluid and reservoir fluid increased. As a result, invasion volume, damage radius, and reduction of recovery factor are increased. It should be noted that, when the specific weight of drilling fluid is larger than 1.1, the increase rate of skin factor tends to decreases. Overall, the effects of drilling fluid properties on the formation damage is significantly smaller than that of reservior permeability.

\section{Effects of soaking period on fluid invasion}

Figure 10 shows the effects of soaking time on the damage radius, invasion volume, skin factor, and reduction of recovery factor. As we expected, when the reservoir matrix is exposed to the drilling fluid for a longer period, the invasion volume and damage radius are larger due to larger imbibition time, which also induces a larger skin factor and reduces the recovery factor of the reservoir. Especially, at the early soaking time (within 12 days), the skin factor increases sharply. Therefore, extremely caution should be paid to avoid longer soaking period during the drilling operation in low permeability reservoirs.

\section{Conclusion}

(1) Due to the low permeability and capillary hysteresis during imbibition, the invasion depth of drilling fluid is usually in the range of $1.7-2.5 \mathrm{~m}$. Although the invasion depth is small, the formation damage has a significant effect on the recovery factor due to the small seepage area in the near-well region. Compared with the case without considering formation damage, the recovery factor of the case considering formation damage decreased $3 \%$.
(2) When formation damage is considered, the pressure distribution from wellbore to deep reservoir exhibits three stages. Besides the two stages including a constant pressure in the far end of the reservoir and a pressure-drop cone within the pressure interference region, a sharper reduction of pressure in the near-well region can be observed where the flowing resistance of hydrocarbon is increased by the invasion of drilling fluid.

(3) Using oil-bearing drilling fluid with a higher viscosity and lower specific weight can decrease the formation damage due to the invasion of drilling fluid. The effects of drilling fluid properties on the formation damage is significantly smaller than that of reservoir permeability. Extreme caution should be paid to avoid long soaking period during the drilling operation in low permeability reservoirs.

Funding We acknowledge the National Science and Technology Major Projects of China (2016ZX05023-005-001-003) and the National Natural Science Foundation Projects of China (51474070).

\section{Declarations}

Conflict of interest We declare that we do not have any commercial or associative interest that represents a conflict of interest in connection with the work submitted.

Open Access This article is licensed under a Creative Commons Attribution 4.0 International License, which permits use, sharing, adaptation, distribution and reproduction in any medium or format, as long as you give appropriate credit to the original author(s) and the source, provide a link to the Creative Commons licence, and indicate if changes were made. The images or other third party material in this article are included in the article's Creative Commons licence, unless indicated otherwise in a credit line to the material. If material is not included in the article's Creative Commons licence and your intended use is not permitted by statutory regulation or exceeds the permitted use, you will need to obtain permission directly from the copyright holder. To view a copy of this licence, visit http://creativecommons.org/licenses/by/4.0/. 


\section{References}

Ahmad HM, Kamal MS, Murtaza M, Al-Harthi MA (2017) Improving the drilling fluid properties using nanoparticles and watersoluble polymers. In: SPE Kingdom of Saudi Arabia annual technical symposium and exhibition. Society of Petroleum Engineers

Al-Yaseri AZ et al (2015) Pore-scale analysis of formation damage in Bentheimer sandstone with in-situ NMR and micro-computed tomography experiments. J Pet Sci Eng 129:48-57

Amani M, Al-Jubouri M, Shadravan A (2012) Comparative study of using oil-based mud versus water-based mud in HPHT fields. Adv Pet Explor Dev 4(2):18-27

Arhuoma M, Dong M, Yang D, Idem R (2009) Determination of water-in-oil mulsion viscosity in porous media. Ind Eng Chem Res 8(15):7092-7102

Ballard T, Dawe R (1988) Wettability alteration induced by oil-based drilling fluid. In: PE formation damage control symposium. Society of Petroleum Engineers

Bazin B, Peysson Y, Lamy F et al (2010) In-situ water-blocking measurements and interpretation related to fracturing operations in tight gas reserviors. SPE Prod Oper 25(4):431-437

Caenn R, Chillingar GV (1996) Drilling fluids: state of the art. J Pet Sci Eng 14(3-4):221-230

Cai J, Yu B, Zou M, Mei M (2010) Fractal analysis of invasion depth of extraneous fluids in porous media. Chem Eng Sci 65:5178-5186

Civan F (1998) Incompressive cake filtration: mechanism, parameters, and modeling. AIChE J 44:2379-2387

Clark PE (1995) Drilling mud rheology and the API recommended measurements. In: SPE reduction operations symposium. Society of Petroleum Engineers

Coskuner G (2004) Drilling induced formation damage of horizontal wells in tight gas reservoirs. J Can Pet Technol 43(11):13-18

Dias FTG, Souza RR, Lucas EF (2015) Influence of modified starches composition on their performance as fluid loss additives in invertemulsion drilling fluids. Fuel 140:711-716

Ding Y, Longeron D, Renard G, Audibert A (2004) Modeling of both near-wellbore damage and natural cleanup of horizontal wells drilled with water-based drilling fluids. SPE Drill Eng 9:252-264

Doty P (1986) Dow, clear brine drilling fluids: a study of penetration rates, formation damage, and wellbore stability in full-scale drilling tests. SPE Drill Eng 1:17-30

Frequin D, Bedrikovetsky P, Zitha PL (2013) CT scan study of the leak-off of oilbased drilling fluids into saturated media. In: SPE European formation damage conference \& exhibition. Society of Petroleum Engineers

Growcock F, Ellis C, Schmidt D, Azar J (1994) Electrical stability, emulsion stability, and wettability of invert oil-based muds. SPE Drill Complet 9(01):39-46

Iscan AG, Civan F, Kok MV (2007) Alteration of permeability by drilling fluid invasion and flow reversal. J Pet Sci Eng 58:227-244

Jiao D, Sharma MM (1994) Mechanism of cake buildup in crossflow filtration of colloidal suspensions. J Colloid Interface Sci 162:454-462

Jilani S, Menouar H, Al-Majed A, Khan M (2002) Effect of overbalance pressure on formation damage. J Pet Sci Eng 36:97-109

Jin L (2009) Quantitative formation damage evaluation using dynamic/ static drilling fluid filtration tests data. In: SPE/IADC drilling conference and exhibition, Amsterdam, The Netherlands, p 8

Kamal MS, Mahmoud M, Hanfi M et al (2019) Clay minerals damage quantification in sandstone rocks using core flooding and NMR. J Pet Explor Prod Technol 9(1):593-603

Li XR, Zhang Y (2018) Supercritical water oxidation of waste drilling fluid. Fresenius Environ Bull 27:1884-1888
Li X, Yan X, Kang Y (2017) Investigation of drill-in fluids damage and its impact on wellbore stability in Longmaxi shale reservoir. J Pet Sci Eng 159:702-709

Liang T, Gu F, Yao E et al (2017) Formation damage due to drilling and fracturing fluids and its solution for tight naturally fractured sandstone reservoirs. Geofluids 2017:1-9

Lu X, Bo Cao, Xie K et al (2021) EOR mechanisms of polymer flooding in a heterogeneous oil reservoir. Pet Explor Dev 48(1):148-155

Lyu C, Ning Z, Wang Q et al (2018) Application of NMR T2 to pore size distribution and movable fluid distribution in tight sandstones. Energy Fuels 32(2):1395-405

Mahmoud M, Elkatatny S, Abdelgawad KZ (2016) Using high- and low-salinity seawater injection to maintain the oil reservoir pressure without damage. J Pet Explor Prod Technol 7(2):589-596

Parn-Anurak S, Engler TW (2005) Modeling of fluid filtration and near-wellbore damage along a horizontal well. J Pet Sci Eng 46:149-160

Ramézani Hamidréza, Akkal R, Cohaut N et al (2015) On the filtrate drilling fluid formation and near well-bore damage along the petroleum well. J Pet Sci Eng 135:299-313

Shabani A, Jahangiri HR, Shahrabadi A (2019) Data-driven approach for evaluation of formation damage during the injection process. J Pet Explor Prod Technol 10(2):699-710

Su Y, Zha M, Ding X et al (2018) Pore type and pore size distribution of tight reservoirs in the Permian Lucaogou Formation of the Jimsar Sag, Junggar Basin, NW China. Mar Pet Geol 89:761-774

Suryanarayana P, Wu Z, Ramalho J, Himes R (2007) Dynamic modeling of invasion damage and impact on production in horizontal wells. SPE Reserv Eval Eng 10:348-358

Van Overveldt AS, Guo H, de Blok G, Bedrikovetsky P, Zitha PL (2012) A CT scan study of the leakoff of oil-based drilling fluids. In: SPE international symposium and exhibition on formation damage control. Society of Petroleum Engineers

Waldmann AT, Martins AL, Aragao AF, Lomba RF (2005) Predicting and monitoring fluid invasion in exploratory drilling. SPE Drill Complet 20(04):268-275

Whitaker S (1996) The forchheimer equation: a theoretical development. Transp Porous Med 25:27-61

Windarto AYG, Sukarno P, Soewono E (2011) Modeling of mud filtrate invasion and damage zone formation. J Pet Sci Eng 77:359-364

Windarto AYG, Sukarno P, Soewono E (2012) Modelling of formation damage due to mud filtrate invasion in a radial flow system. J Pet Sci Eng 100:99-105

Xu C, Kang Y, You Z, Chen M (2016) Review on formation damage mechanisms and processes in shale gas reservoir: known and to be known. J Nat Gas Sci Eng 36:1208-1219

Yan J, Monezes J, Sharma MM (1993) Wettability alteration caused by oil-based muds and mud components. SPE Drill Complet 8(01):35-44

Zhang T, Li X, Li J et al (2017) Numerical investigation of the well shut-in and fracture uncertainty on fluid-loss and production performance in gas-shale reservoirs. J Nat Gas Sci Eng 46:421-435

Zhang X, You L, Kang Y et al (2020a) Formation damage control of saline-lacustrine fractured tight oil reservoir during well drilling. Arab J Geosci 13(20):1087

Zhang T, Javadpour F, Yin Y et al (2020b) Upscaling water flow in composite nanoporous shale matrix Using Lattice Boltzmann method. Water Resour Res. https://doi.org/10.1029/2019WR0260 07

Zhao D, Guo Y, Chong X, Li G, Wang Y (2019) Nuclear magnetic resonance experiment analysis of tight gas sandstone reservoir. Fresenius Environ Bull 28:220-225

Publisher's Note Springer Nature remains neutral with regard to jurisdictional claims in published maps and institutional affiliations.

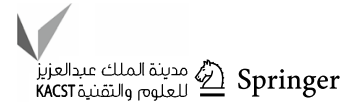

